pregnancy. The patient should first be made euthyroid by drugs and the vascularity of the gland then reduced by giving a short course of potassium iodide in the minimum effective dose (about $5 \mathrm{mg}$ three times daily). ${ }^{26}$ After surgery, replacement thyroxine should be given to eliminate the risk of maternal hypothyroidism for the rest of the pregnancy. Radioactive iodine is absolutely contraindicated. Thiourea drugs are secreted in milk, so women taking them should not breast-feed.

Finally, recent reports from Japan by Amino and colleagues ${ }^{27} 28$ point to an influence of pregnancy on the course of autoimmune thyroid disease and suggest that women predisposed to autoimmune thyroid disease may be particularly at risk after delivery. They described 25 episodes of primary hypothyroidism in 23 women in the postpartum period; in all but three it was transient and recovery was spontaneous 5-10 months later. ${ }^{26}$ Thyroid enlargement and the presence of antithyroid microsomal (not antithyroglobulin) antibodies were characteristic features, in conjunction with thyroid function test results typical of primary hypothyroidism. They also reported a recurrence of transient hyperthyroidism in four women with Graves's disease in the postpartum period, ${ }^{28}$ with evidence of increasing autoimmune disturbance. In one case the episode was followed by hypothyroidism, also transient. The immune state in the mother is altered during pregnancy, ${ }^{29}$ probably partly because of hormone changes, and other autoimmune diseases are known to remit during pregnancy and relapse post partum ${ }^{30}{ }^{31}$. These findings indicate that women with a history of autoimmune thyroid disease should be watched closely post partum, but that even in those who become hypothyroid treatment may be required for only a short period.

${ }^{1}$ Crooks, J, et al, Lancet, 1964, 2, 334.

2 Crooks, J, et al, Lancet, 1967, 2, 625.

3 Aboul-Khair, S A, et al, Clinical Science, 1964, 27, 195.

4 Pochin, E E, Clinical Science, 1952, 11, 441.

5 Halnan, K E, Clinical Science, 1958, 17, 281.

- Kenimer, J G, Hersham, J M, and Higgins, M P, fournal of Clinical Endocrinology and Metabolism, 1975, 40, 491.

7 Hershman, J M, and Burrow, G N, Fournal of Clinical Endocrinology and Metabolism, 1976, 42, 970 .

${ }^{8}$ Braunstein, G D, and Hershman, J M, fournal of Clinical Endocrinology and Metabolism, 1976, 42, 1123.

9 Higgins, H P, and Hershman, J M, Clinics in Endocrinology and Metabolism, $1978,7,167$.

${ }^{10}$ Dowling, J T, Freinkel, N, and Ingbar, S H, fournal of Clinical Investigation, 1960, 39, 1119.

11 Tunbridge, W M G, and Hall, R, Clinics in Obstetrics and Gynaecology, $1975,2,381$.

12 Fisher, D A, and Dussault, J H, Handbook of Physiology Sect 7, Endocrinology, vol 3, p 21. Washington, American Physiological Society, 1974.

${ }^{13}$ Fisher, D A, et al, Recent Progress in Hormone Research, 1977, 33, 59.

14 Abuid, J L, et al, fournal of Clinical Endocrinology and Metabolism, 1974, 39, 263.

15 Fisher, D A, and Odell, W D, fournal of Clinical Investigation, 1969, 48, 1670 .

16 Chopra, I J, fournal of Clinical Investigation, 1974, 54, 583.

17 Chopra, I J, Sack, J, and Fisher, D A, Fournal of Clinical Investigation, $1975,55,1137$.

${ }^{18}$ Montgomery, D A D, and Harley, J M G, Clinics in Obstetrics and Gynaecology, 1977, 4, 339.

${ }^{19}$ Echt, C R, and Doss, J F, Obstetrics and Gynecology, 1963, 22, 615.

${ }^{20}$ Man, E B, et al, fournal of Clinical Investigation, 1951, 30, 137.

21 Osorio, C, and Myant, N B, British Medical Bulletin, 1960, 16, 159

22 Burrow, G N, Clinics in Endocrinology and Metabolism, 1978, 7, 115.

${ }^{23}$ Rosenberg, D, Grand, M J H, and Silbert, D, New England fournal of Medicine, 1963, 268, 292.

24 Nutt, J, et al, British Medical fournal, 1974, 4, 695.

${ }_{25}$ Mutjaba, Q, and Burrow, G N, Clinics in Obstetrics and Gynaecology, 1975, 46, 282.

${ }^{26} \mathrm{Hall}, \mathrm{R}$, et al, Fundamentals of Clinical Endocrinology, p 122. Tunbridge Wells, Pitman Medical, 1974.

27 Takai, S, et al, Annals of Internal Medicine, 1977, 87, 155.

28 Amino, N, et al, fournal of Clinical Endocrinology and Metabolism, 1977, 44, 130.

${ }^{29} \mathrm{Beer}, \mathrm{A} \mathrm{E}$, and Billingham, R E, Advances in Immunology, 1971, 14, 1.

${ }^{30}$ Oka, M, Annals of the Rheumatic Diseases, 1953, 12, 227.

31 Garsenstein, M, Pollak, V E, and Kark, R M, New England fournal of Medicine, 1962, 267, 165.

\section{Hypnosis in the NHS}

Hypnosis has had a chequered history since the days of Mesmer ${ }^{1}$ and his theory of animal magnetism. Braid ${ }^{2}$ maintained that the phenomenon was a form of sleep. Janet ${ }^{3}$ and Bernheim ${ }^{4}$ advanced the ideas of dissociation and suggestion. Charcot $^{5}$ discovered the psychogenic nature of hysteria, and subsequently the ideas of Breuer $^{6}$ and of Freud ${ }^{6}$ - psychodynamic exploration, catharsis, and the discovery of the transference-were derived from investigations into the hypnotic state. Nevertheless, when Freud stopped using hypnosis it was left to exploitation by charlatans and stage performers. Indeed, the lack of medical interest led to the Hypnotism Act of $1952,{ }^{7}$ which placed the onus of permitting performances of hypnotism on local licensing authorities.

Hypnosis came back into clinical use with the development of the behavioural school of psychotherapy, ${ }^{8}$ which added desensitisation to the Freudian methods. Well-defined techniques are now laid down for treatment. ${ }^{9}$ Hypnosis has been shown of value as an additional psychotherapeutic weapon in treating the neuroses; in relieving anxiety, phobic, obsessional, and hysterical symptoms; in psychosomatic illness; and in a large range of personality problems-as well as in obstetrics, dermatology, and dentistry, and for relieving physical pain.

It is now 25 years since the Psychological Medicine Group Committee of the BMA appointed a subcommittee to consider the medical use of hypnosis. ${ }^{10}$ The report confirmed that "hypnotism may be the treatment of choice in some cases of psychosomatic disorder and psychoneurosis. It may be of value for revealing unrecognised motives and conflicts in such conditions .... it has proved its ability to remove symptoms and to alter morbid habits of thought and behaviour." The subcommittee recommended that a description of hypnotism and its psychotherapeutic possibilities, limitations, and dangers should be given to medical undergraduates and instruction in the clinical use be given to all postgraduate psychiatric trainees and possibly trainee anaesthetists and obstetricians.

Yet a recent survey ${ }^{11}$ of training in medical hypnosis in 33 medical schools and 18 dental schools in Britain showed that only two of each group provided official undergraduate training; and three of the medical schools but no dental schools provided official postgraduate training. Clearly little action has been taken to carry out the subcommittee's recommendation: the teaching of hypnosis within the psychiatric services of the NHS is very limited. Nevertheless, the British Society of Medical and Dental Hypnosis is open to membership to doctors and dentists both in the NHS and in the private sector, and a section of medical and dental hypnosis has now been formed within the Royal Society of Medicine.

More doctors are now treating neurotic problems using hypnosis, though in hospital practice its use remains limited to psychiatrists who have the skill and to a few specially trained psychologists working in psychiatric units under the clinical responsibility of a consultant psychiatrist.

This revival of medical interest in hypnosis is likely to be paralleled by an increase in treatment by lay therapists. The indiscriminate use of hypnosis can be harmful, and the 1952 Bill $^{7}$ will need amendment if the public is to be protected from potentially dangerous non-medical hypnosis.

${ }^{1}$ Mesmer, F A, Mesmerism, translated by V R Myers. London, Macdonald, 1958

${ }^{2}$ Braid, J, Neurypnology; or the Rationale of Nervous Sleep Considered in Relation With Animal Magnetism. London, Redway, 1899.

${ }^{3}$ Janet, P, Psychological Healing, vols I and II. London, George Allen and Unwin, 1925. 
${ }^{4}$ Bernheim, H, Suggestive Therapeutics. A Treatise on the Nature and Uses of Hypnotism, translated by C A Herter. New York, Putman, 1900.

5 Charcot, J M, Oeuvres Complètes, vol IX, Metallothérapie et Hypnotisme. Paris, Bourneville et Brissaud, 1890.

${ }^{6}$ Freud, S, and Breuer, J, On the Physical Mechanisms of Hysterical Phenomena (Collected Papers, S Freud). London, Hogarth Press and Institute of Psychoanalysis, 1940.

${ }^{7}$ Hypnotism Act. An Act to regulate the demonstration of hypnotic phenomena for purposes of public entertainment. London, HMSO, 1952.

8 Wolpe, J, Psychotherapy by Reciprocal Inhibition. Palo Alto, Stanford University Press, 1958.

9 Waxman, D, British Fournal of Medical Psychology, 1975, 48, 339.

10 Subcommittee of the Psychological Medicine Group Committee of the British Medical Association, British Medical fournal, 1955, 1, suppl, appendix X, 190.

11 Scott, D L, Proceedings of the British Society of Medical and Dental Hypnosis, 1978, 4, 1, 13.

\section{Preventing cerebral palsy}

The definition of cerebral palsy covers the whole continuum of brain damage from minimal cerebral dysfunction through cerebral palsy to death. Furthermore, ascertainment of cases varies at different ages owing both to delays in diagnosis and to the fact that some cases are not manifest until school makes increased demands on the child. Consequently estimates of the prevalence of cerebral palsy vary, and how far it can be reduced by preventive measures remains uncertain.

As highlighted in a recent symposium, ${ }^{1}$ there is much current interest in preventing mental handicap, particularly cerebral palsy, which has been the subject of a national advertising campaign. Broadly speaking, there are four major causes of cerebral damage that preventive action can attackjaundice, hypoxia, infection, and trauma. The management of jaundice is one of the success stories of modern medicine. Exchange transfusion and preventing rhesus immunisation ${ }^{2}$ should now ensure that the athetoid form of cerebral palsy associated with kernicterus is a thing of the past.

The early detection of fetoplacental malfunctioning should in theory prevent hypoxic cerebral damage due to placental insufficiency. The advantages of fetal monitoring may be partially offset, however, by false positives, which may lead to early induction of an otherwise normal infant with the increased risks of prematurity. A controlled clinical trial of fetal heart monitoring ${ }^{3}$ has therefore been proposed.

Postnatal hypoxic cerebral damage, which is strongly associated with prematurity, is particularly important in the pathogenesis of the diplegias. Up to $70 \%$ of diplegias are found in the $6 \%$ of infants of low birth weight. ${ }^{4}$ Since 1953 birth notifications have included birth weight, and in that time the neonatal mortality of infants of less than $2500 \mathrm{~g}$ has fallen from 155 to reach 90 per 1000 live births in $1976 .{ }^{5}$ Several recent reports have allayed fears that with increased survival the prevalence of handicap may increase; this achievement is due in part to technological improvements such as continuous blood gas monitoring. ${ }^{6-8}$ These reports came, however, from "centres of excellence," and the prevention of handicap in very small babies who survive is not a universal finding. ${ }^{9}$ Nevertheless, there seem to have been three phases ${ }^{10}$ in the development of neonatal medicine. Firstly, infants of very low birth weight or with serious complications died. Later, more survived but a large proportion of the survivors suffered major handicap. The third phase, now starting, achieves both increased survival and lower handicap rates. When all special-care units achieve these results cerebral palsy is likely to be appreciably reduced.
Damage to the brain as a result of infection or trauma most often results in a hemiplegia. The infection may directly affect the central nervous system either during intrauterine development (rubella, toxoplasmosis) or postnatally (meningitis, encephalitis). Cerebral damage may also occur secondary to convulsions. Preventive measures include rubella immunisation and the early and adequate management of infections; traumatic damage should be reduced in some instances with better obstetric care. The acquired hemiplegias, however, make up a relatively small proportion of all cases of cerebral palsy, so that the impact of such general measures on overall prevalence will be small.

Retrospective studies of large series of cases of cerebral palsy have shown that in nearly half there were potentially preventable or treatable perinatal hazards that seemed to have caused later handicap. In almost one-third premature delivery or low birth weight was thought to be the primary cause. ${ }^{11} \mathrm{~A}$ forward-looking estimate, based on what is currently known about causes, has suggested that $25-40 \%$ of cases of cerebral palsy may be preventable. ${ }^{12}$ The right of every infant to have access to special care if necessary has financial implications and must cast doubt on the proposed economies in the maternity services. ${ }^{1314}$

Despite recent advances in obstetrics and neonatal medicine and their potential for preventing cerebral palsy, nothing is known in Britain about changes in the incidence of the syndrome. One series from Sweden ${ }^{15}$ showed that between 1954 and 1970 the incidence fell successively and significantly from $2 \cdot 2$ to $1 \cdot 3$ per 1000 . This improvement was predominantly due to a decrease in the numbers of spastic and ataxic diplegias among infants of low birth weight. A similar study ${ }^{16}$ examining trends in Western Australia from 1956 to 1975 showed a rise in incidence in the period 1966-70 followed by a highly significant fall after 1970 . We now need a comparable examination of trends in Britain, together with some form of continuous monitoring. Routine follow-up of low-birthweight infants is one possible method. Such infants account for only a small proportion of all live-born babies, they are at high risk of cerebral palsy, and the risk is directly associated with the standard of care in the perinatal period. Might such a scheme be tried as an experiment in one or two regions to assess its feasibility?

1 Ciba Foundation Symposium 59, Elsevier, North-Holland, 1978.

${ }^{2}$ Clarke, C A, et al, British Medical fournal, 1963, 1, 979.

3 Lancet, 1978, 2, 510.

4 Childs, B, and Evans, P R, Lancet, 1954, 1, 642

5 DHSS LHS 27/1, Annual Returns.

${ }^{6}$ Rawlings, G, et al, Lancet, 1971, 1, 516.

Davies, P A, and Tizard, J P M, Developmental Medicine and Child Neurology, 1975, 17, 3.

${ }^{8}$ Fitzhardinge, E, et al, Ciba Foundation Series 59, p 139. Elsevier, NorthHolland, 1978 .

${ }^{9}$ Pharoah, P O D, British fournal of Preventive and Social Medicine, 1976, 4, 257.

${ }^{10}$ Reynolds, E O R, Ciba Foundation Series 59, p 77. Elsevier, NorthHolland,

${ }^{11}$ Drillien, C M, Ciba Foundation Series 59, p 17. Elsevier, North-Holland, 1978.

12 Polani, P, address to Spastics Society, Castle Priory, 1973.

13 Priorities for Health and Personal Social Services in England. London, HMSO, 1976

14 The Way Forward. London, HMSO, 1977.

15 Hagberg, B, et al, Acta Paediatrica Scandinavica, 1975, 64, 187.

16 Stanley, F, paper presented to International Cerebral Palsy Society, Aosta, 1978.

\section{Correction: Modified neurosyphilis}

In the leading article on "Modified neurosyphilis" (2 September, p 647) line 7 of the second paragraph should have read "FTA-ABS with over five lymphocytes/ $\mathrm{mm}^{3}$." 